(C) The Author(s), 2020. Published by Cambridge University Press on behalf of The Nutrition Society. This is an Open Access article, distributed under the terms of the Creative Commons Attribution licence (http://creativecommons.org/licenses/by/4.0/), which permits unrestricted re-use, distribution, and reproduction in any medium, provided the original work is properly cited.

\title{
Effects of maternal supplementation with fully oxidised $\beta$-carotene on the reproductive performance and immune response of sows, as well as the growth performance of nursing piglets
}

\author{
Jun Chen ${ }^{1}$, Jiaming Chen ${ }^{1}$, Yinzhi Zhang ${ }^{1}$, Yantao Lv $^{1}$, Hanzhen Qiao ${ }^{1}$, Min Tian ${ }^{1}$, Lin Cheng ${ }^{1}$, Fang Chen ${ }^{1}$, \\ Shihai Zhang ${ }^{1}$ and Wutai Guan ${ }^{1,2 *}$ \\ ${ }^{1}$ Guangdong Provincial Key Laboratory of Animal Nutrition Control, College of Animal Science, South China Agricultural \\ University, Guangzhou 510642, Guangdong Province, People's Republic of China \\ ${ }^{2}$ College of Animal Science and National Engineering Research Center for Breeding Swine Industry, South China Agricultural \\ University, Guangzhou 510642, Guangdong Province, People's Republic of China
}

(Submitted 12 April 2020 - Final revision received 23 June 2020 - Accepted 30 June 2020 - First published online 14 August 2020)

Abstract

The present study was conducted to evaluate the impact of dietary fully oxidised $\beta$-carotene $\left(\mathrm{OxBC}, \mathrm{C}_{40} \mathrm{H}_{60} \mathrm{O}_{15}\right)$ supplementation during the perinatal period on immune status and productivity in a sow model. At day 85 of pregnancy, 150 sows were allocated to one of three dietary treatments with fifty sows per treatment. The three experimental diets were supplemented with 0,4 or $8 \mathrm{mg} / \mathrm{kg}$ OxBC in the basal diet. The feeding trial was conducted from gestation day 85 until day 21 of lactation. Dietary OxBC supplementation greatly enhanced colostrum IgM, IgA and IgG levels, and the IgM and IgG content of 14-d milk. Dietary OxBC supplementation decreased the TNF- $\alpha$ and IL-8 levels in colostrum, as well as the TNF- $\alpha$ and IL-18 levels in 14-d milk. There was also a tendency towards an increase in the soluble CD14 level in 14-d milk. Although dietary treatments did not affect average daily feed intake nor backfat thickness loss during lactation, dietary OxBC supplementation tended to enhance litter weight and individual piglet weight at weaning. There was a trend towards increased lactose concentration in 14-d milk with increasing dietary OxBC. It is concluded that dietary supplementation with OxBC during the perinatal period enhances the lactose concentration of sow milk and the immune status of sows, which is reflected by improved cytokine status and immunoglobulin concentrations in colostrum and milk, and thus tending to increase litter weight and individual piglet weight at weaning. The results also provide a scientific nutritional reference for perinatal mothers due to the biological similarity between pigs and humans.

Key words: Fully oxidised $\beta$-carotene: Immune status: Sow models: Offspring weaning weight

During late gestation and lactation, sows have a high energy demand and an increased oxygen requirement due to rapid differentiation of the secretory parenchyma, intense mammary gland growth, and milk synthesis and secretion ${ }^{(1)}$. Perinatal sows have a heavy metabolic load and suffer from a metabolic syndrome with poor immunity ${ }^{(2-4)}$, and this metabolic syndrome is indicative of a low-grade systemic inflammatory condition ${ }^{(5)}$. The percentage of granulocytes and phagocytic monocytes in the whole blood of sows is lowest at farrowing and significantly increases within the ensuing 21 (SEM 3) $\mathrm{d}^{(2)}$. Gene expression of pro-inflammatory cytokines in mammary tissues is downregulated at farrowing in sows ${ }^{(3)}$.

These stresses provide a strong rationale for the use of nutritional strategies aimed at ameliorating the immunological and metabolic health of perinatal sows. A recently discovered group of compounds derived from $\beta$-carotene represent a potential solution to help optimise the health of perinatal sows. The compounds, which are copolymers of $\beta$-carotene and oxygen, were discovered by research aimed at understanding the mechanisms behind the vitamin-A-independent effects of $\beta$-carotene. That research yielded several important findings about the nature of $\beta$-carotene oxidation. The first was that $\beta$-carotene undergoes complete and spontaneous oxidation to yield a complex mixture of compounds characterised by a predominance of various $\beta$-carotene-oxygen copolymers combined with minor amounts of smaller molecular weight norisopenoids ${ }^{(6)}$. While norisoprenoids are well-known products of $\beta$-carotene oxidation, the presence and predominance of the copolymers was a new discovery. The second discovery relates to the biological activity of the compound mixture, which is termed oxidised

Abbreviations: ADG, average daily gain; OxBC, oxidised $\beta$-carotene; sCD14, soluble CD14.

* Corresponding author: Wutai Guan, email wtguan@scau.edu.cn 
$\beta$-carotene (OxBC). In vitro and in vivo studies demonstrated the presence of immune modulating activities for OxBC, including the ability to (1) prime the innate immune system and (2) limit the extent of inflammation ${ }^{(7,8)}$. Furthermore, the newly discovered copolymers were shown to be responsible for the innate immunological activities of $\mathrm{OxBC}$, while the norisoprenoids appeared to be inert with regard to immunological activity ${ }^{(7)}$. OxBC is devoid of intact $\beta$-carotene and does not possess vitamin A nor the provitamin A or antioxidant activities of $\beta$-carotene, and therefore its mode of actions is unique and distinct relative to those of $\beta$-carotene ${ }^{(6,7)}$.

Previous trials to evaluate the effects of OxBC in livestock have been conducted in piglets, dairy calves and broiler chickens. Dietary supplementation with OxBC improved growth performance of vaccinated (porcine reproductive and respiratory syndrome; PRRS) and non-vaccinated piglets and resulted in significant anti-inflammatory activity in the lungs of Mannheimia haemolytica-challenged dairy calves ${ }^{(8,9)}$. Most recently, Kang et al. found that dietary supplementation with OxBC reduced the impact of subclinical necrotic enteritis and enhanced the body weight of broilers ${ }^{(10)}$.

Taken together, the presence and natural occurrence of the copolymers, their immunological activity and their effect on animal health have led to the suggestion that these compounds may be the actual source of the vitamin A-independent effects of $\beta$-carotene ${ }^{(6-8,11,12)}$.

The demonstrated immunological and anti-inflammatory benefits of dietary OxBC observed in piglets, dairy calves and poultry provide a strong rationale for testing in perinatal sows. Therefore, the present study was conducted to test our hypothesis that maternal dietary OxBC supplementation during the perinatal period would improve the immune status of sows, and afterwards health and the growth of suckling piglets. The results will also provide a scientific nutritional reference for perinatal mothers due to the biological similarity between pigs and humans ${ }^{(13,14)}$.

\section{Materials and methods}

\section{Animals and experimental design}

All animal protocols used in the present study were approved by the South China Agricultural University Institutional Animal Care and Use Committee. This feeding trial was conducted in a subtropical climate area $\left(113.20^{\circ} \mathrm{E}, 22.24^{\circ} \mathrm{N}\right)$ between July and September, 2017. At gestation day 85, a total of 150 multiparous sows (Landrace $\times$ Yorkshire), ranging from 3rd to 8 th parity, were randomly allotted by parity, historical reproductive performance and date of predicted parturition into three dietary treatments with fifty replicates (sows) per treatment. The three experimental diets were supplemented with 0,4 or $8 \mathrm{mg} / \mathrm{kg}$ OxBC (Avivagen), respectively (all without additional medications). The OxBC product is a $10 \%$ premix with a maize starch (90\%) carrier. Low parts-per-million level supplementation of OxBC in livestock feeds has been shown to provide clear benefits in poultry and piglets ${ }^{(9,10)}$. In broiler chickens, OxBC provided in feed at 2,4 and $6 \mathrm{mg} / \mathrm{kg}$ levels over $28 \mathrm{~d}$ had a restorative effect upon productivity negatively affected by a subclinical necrotic enteritis challenge induced by Clostridium perfringens $^{(9)}$. In PRRS-vaccinated pigs, diet containing $10 \mathrm{mg} / \mathrm{kg}$ OxBC significantly improved average daily gain (ADG) and feed conversion ratio by 12.2 and $7.9 \%$, respectively, compared with vaccinated, non-supplemented controls. In non-vaccinated animals, supplementation with $10 \mathrm{mg} / \mathrm{kg}$ OxBC improved ADG by $4.3 \%$ and significantly improved feed conversion ratio by $9.2 \%$ relative to non-supplemented, non-vaccinated controls ${ }^{(10)}$. Therefore, we selected the dosage of OxBC supplemented in the diets $(0,4$ and $8 \mathrm{mg} / \mathrm{kg})$ in the present study. The feeding trial was carried out from gestation day 85 until day 21 of lactation (at weaning).

\section{Diets and management}

A basal commercialised maize-soyabean meal diet (Table 1), formulated to meet or exceed the National Research Council ${ }^{(15)}$ requirements for gestating and lactating sows, served as the basal diet (control diet) for treatment group 1. For treatment groups 2 and 3, OxBC was added to the basal diet at 4 and $8 \mathrm{mg} / \mathrm{kg}$, respectively. Fully OxBC is a carotenoid derivative $\left(\mathrm{C}_{40} \mathrm{H}_{60} \mathrm{O}_{15}, 85 \%\right)$ that is produced by the complete, spontaneous oxidation of $\beta$-carotene. The OxBC that was administered through the feed was purchased from Avivagen Inc. OxBC was added to the basal diet at the expense of maize. From day 85 to day 112 of gestation, sows were housed in gestation

Table 1. Composition and nutrient content of the basal diet (as-fed basis) (Percentages)

\begin{tabular}{lr}
\hline Ingredient & Content (\%) \\
\hline Maize & $58 \cdot 64$ \\
Soyabean meal, 43.0\% crude protein & 23.36 \\
Wheat bran, 15.7\% crude protein & 8.00 \\
Fish meal, 62.8\% crude protein & $2 \cdot 00$ \\
Soyabean oil & 4.00 \\
Calcium carbonate & 1.48 \\
Dicalcium phosphate & 0.30 \\
Phytase & 0.02 \\
Salt & 0.30 \\
Sodium bicarbonate & 0.30 \\
Sodium sulphate & 0.20 \\
Choline chloride & 0.10 \\
L-Lys.HCl (98.5\%) & 0.21 \\
DL-Met (98.0\%) & 0.05 \\
L-Thr (98.5\%) & 0.02 \\
Vitamin and mineral premix \\
Carrier (calcium carbonate) & 0.90 \\
Total & 0.12 \\
Calculated nutritional level & 100.00 \\
Dietary energy (kcalt/kg) & \\
Crude protein (\%) & 3420 \\
Ca (\%) & 17.9 \\
Total P (\%) & 1.02 \\
Available P (\%) & 0.79 \\
Lys (\%) & 0.55 \\
Met + Cys (\%) & 0.96 \\
Thr (\%) & 0.57 \\
Trp (\%) & 0.66 \\
\hline & 0.23 \\
\hline
\end{tabular}

* Vitamin and mineral premix provided following per kg of diet: vitamin A $4.0 \mathrm{mg}$, vitamin D $75.0 \mu \mathrm{g}$, vitamin E $60.1 \mathrm{mg}$, vitamin $\mathrm{K} 4.0 \mathrm{mg}$, vitamin $B_{1} 3.0 \mathrm{mg}$, vitamin $B_{2}$ $10 \mathrm{mg}$, vitamin $B_{6} 4 \mathrm{mg}$, vitamin $B_{12} 40 \mu \mathrm{g}$, nicotinic acid $50 \mathrm{mg}$, pantothenic acid $30 \mathrm{mg}$, folic acid $4 \mathrm{mg}$, biotin $0.45 \mathrm{mg}$; Cu (copper sulphate) $30 \mathrm{mg}$, Fe (ferrous sulphate) $100 \mathrm{mg}$, iodine (calcium iodate) $0.25 \mathrm{mg}, \mathrm{Zn}$ (zinc sulphate) $100 \mathrm{mg}, \mathrm{Mn}$ (manganese sulphate) $40 \mathrm{mg}$, Se (sodium selenite) $0.25 \mathrm{mg}$. † To convert energy values from kcal to kJ, multiply by $4 \cdot 184$. 
stalls and provided with $3.0 \mathrm{~kg}$ of feed daily. At $2 \mathrm{~d}$ prepartum, sows were transported to farrowing crates and fed ad libitum until weaning at lactation day 21 .

\section{Sample collection and determination: sow productivity}

At parturition, reproductive performance data were recorded, including the total number of piglets born, the number born alive and the number of weak animals (birth weight less than $0.7 \mathrm{~kg}$ ), stillborn and mummies, and deformed piglets. Litter birth weight and individual birth weights were recorded. Within $24 \mathrm{~h}$ postparturition, piglets per litter were adjusted within treatment groups.

At weaning (day 21 of lactation), the number of pigs weaned, litter weight, individual pig weight and ADG of piglets were all recorded. The survival rate of piglets, the incidence of piglet diarrhoea, lactation ADG of sows and the oestrus rate to $7 \mathrm{~d}$ postweaning were all recorded. In addition, backfat thickness was measured on day 85 and day 110 of gestation and on day 21 of lactation.

\section{Serology}

Blood samples were collected from a subset of sows ( $n$ 10) from each dietary treatment. The sows were randomly chosen, and blood $(10 \mathrm{ml})$ was collected by ear venipuncture at 85 - $\mathrm{d}$ postcoitus and at 0-d, 14-d and 21-d postpartum. The same subset of sows was bled at each time period. Sow's blood was processed for leucocyte phagocytic activity at all four time points (85-d post-coitus, $0-d, 14-d$ and 21-d postpartum). Leucocyte phagocytic activities were determined using a flow cytometer by Phago test kit.

\section{Colostrum and milk samples}

Colostrum was collected from functional glands within $12 \mathrm{~h}$ postpartum and after intramuscular injection of $20 \mathrm{IU}$ oxytocin postpartum on day 14 and day 18, respectively. Colostrum and milk were collected from the same sows selected for blood sample collection. Approximately $30 \mathrm{ml}$ was collected each time. Colostrum and 14-d milk were processed for determination of somatic cell count and nutritional composition, immunoglobulin and cytokine levels. The 18-d milk sample was prepared to detect its OxBC content.

\section{Response indexes: sow productivity}

All criteria were recorded or measured, covering the number of piglets born (total, live, weak (body weight $<0.7 \mathrm{~kg}$ ), stillborn, mummified and deformed), litter weight and individual body weight at birth. We also recorded litter weight and individual body weight at weaning, ADG of piglets from birth to weaning, the number of piglets weaned, pre-weaning piglet survival and the diarrhoea rate of piglets.

\section{Lactation feed intake and backfat thickness of sows}

The average daily feed intake of the sows during lactation was recorded. The backfat thickness at day 85 and day 110 of gestation and at day 21 of lactation was measured using a Pig Backfat Meter (Renco), and backfat loss during lactation was calculated.
Neutrophil phagocytic activity in the whole blood of sows

The neutrophil phagocytic activity in whole blood at day 85 of gestation, at farrowing and on day 14 and day 21 of lactation was measured using a flow cytometer (Thermo Fisher) by Phago test kit.

\section{Nutritional composition and somatic cell count in colostrum and milk}

The nutritional composition (fat, solid-not-fat, protein and lactose) in colostrum and milk was measured using a milk analyser. The somatic cell counts in the colostrum and the milk were measured using a flow cytometer (Thermo Fisher).

\section{Immunoglobulin level in colostrum and milk}

IgM, IgA and IgG levels in colostrum and 14-d milk were measured by ELISA via kits supplied by Wuhan Huamei Biotechnology Company.

\section{Cytokine levels in colostrum and milk}

Soluble CD14 (sCD14) and cytokine (TNF $\alpha$, IL-8 and IL-18) levels in colostrum and 14-d milk were measured by ELISA, using kits supplied by Wuhan Huamei Biotechnology Company, and leukotriene-B4 was measured using an ELISA kit supplied by ENZO.

\section{Oxidised $\beta$-carotene content in milk}

The OxBC content in 18-d milk samples was measured by analysing the geronic acid content in the milk. Geronic acid is an indirect, low molecular weight marker indicating the presence of OxBC. The geronic acid method is described in Burton et $a l^{(12)}$, and the multiplying factor is 50 in going from the geronic acid measurement to the calculated $\mathrm{OxBC}^{(12)}$

\section{Statistical analysis}

For all experimental data, except for the oestrus rate of sows, the one-way ANOVA procedure of SPSS 21.0 (SPSS, INC.) was used to determine whether significant variation existed among treatments. When overall differences were found, the least significant difference multiple range test was used to determine the differences between means. The oestrus rate of sows was analysed using a $\chi^{2}$ test. Results were expressed as means with their standard errors, except for the oestrus rate of sows, which was expressed in percentages. Probabilities that were $<0.05$ were regarded as significant, and probabilities ranging from $>0 \cdot 05$ to $<0 \cdot 10$ were regarded as trends or tendencies among treatments.

\section{Results}

\section{Reproductive performance}

As shown in Table 2 , the number of total piglets born, those born alive, weak, stillborn and mummies, and deformed piglets were unaffected by dietary treatment $(P>0.05)$. Litter birth weight and individual birth weight also were not impacted by treatment $(P>0.05)$. Although there were no statistical differences among treatments for oestrus rates of sows during $7 \mathrm{~d}$ post-weaning 
Table 2. Effects of dietary fully oxidised $\beta$-carotene (OxBC) supplementation during late gestation and lactation on reproductive performance of sows ${ }^{*}$ (Mean values with their standard errors; numbers and percentages)

\begin{tabular}{|c|c|c|c|c|c|c|c|c|c|c|}
\hline \multirow[b]{3}{*}{ Items } & \multicolumn{9}{|c|}{ OxBC level (mg/kg) } & \multirow[b]{3}{*}{$P$} \\
\hline & \multicolumn{3}{|c|}{0} & \multicolumn{3}{|c|}{4} & \multicolumn{3}{|c|}{8} & \\
\hline & Mean & & SEM & Mean & & SEM & Mean & & SEM & \\
\hline$n$ & & 50 & & & 50 & & & 50 & & \\
\hline Sow parity & 4.70 & & 0.40 & 4.70 & & 0.39 & 4.71 & & 0.38 & 1.000 \\
\hline No. of total born per litter & 11.40 & & 0.37 & 11.48 & & 0.31 & $11 \cdot 25$ & & 0.33 & 0.907 \\
\hline No. of born alive per litter & 10.60 & & 0.33 & 10.55 & & 0.28 & 10.58 & & 0.33 & 0.995 \\
\hline No. of weak piglets per litter* & 0.40 & & 0.10 & 0.35 & & 0.08 & 0.27 & & 0.09 & 0.689 \\
\hline No. of stillborn and mummies per litter & 0.67 & & 0.16 & 0.77 & & 0.17 & 0.56 & & 0.14 & 0.630 \\
\hline No. of deformed piglets per litter & 0.12 & & 0.05 & 0.16 & & 0.07 & 0.17 & & 0.07 & 0.852 \\
\hline Litter birth weight (kg) & 16.45 & & 0.46 & $17 \cdot 10$ & & 0.35 & 16.97 & & 0.53 & 0.580 \\
\hline Individual birth weight $(\mathrm{kg})$ & 1.47 & & 0.03 & 1.51 & & 0.03 & 1.53 & & 0.03 & 0.421 \\
\hline Oestrus rate of sows during $7 \mathrm{~d}$ post-weaning (\%) & & $85 \cdot 71$ & & & $90 \cdot 70$ & & & 91.67 & & 0.886 \\
\hline
\end{tabular}

* Weak pigs refer to those that were $<0.70 \mathrm{~kg}$ at birth.

Table 3. Effects of dietary fully oxidised $\beta$-carotene (OxBC) supplementation during late gestation and lactation on lactation performance of sows (Mean values with their standard errors; numbers)

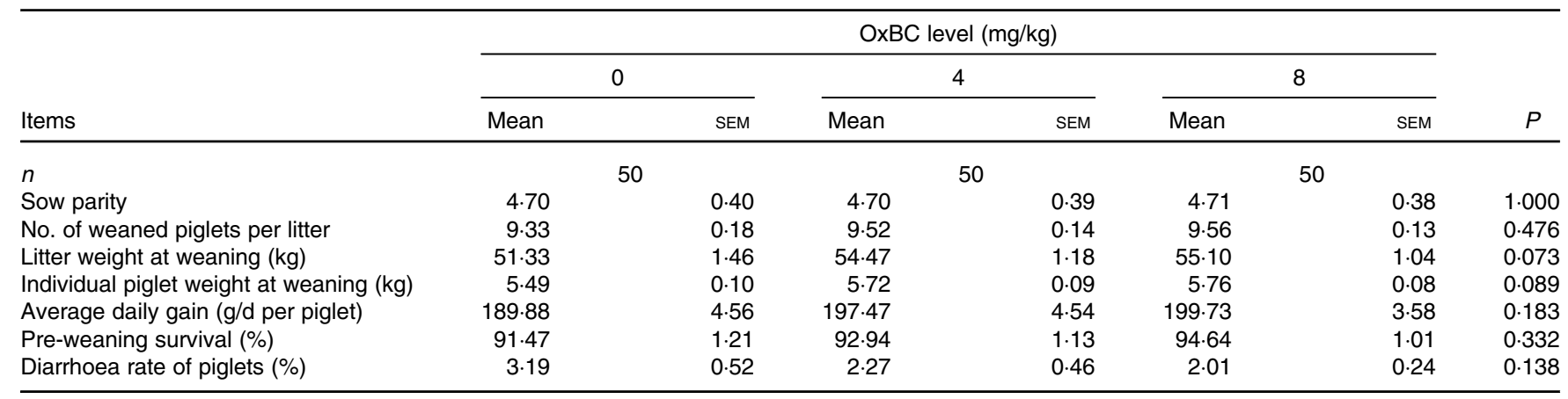

$(P>0.05)$, sows fed 4 and $8 \mathrm{mg} / \mathrm{kg}$ OxBC had numerically higher return to oestrus rates ( 4.99 and $5.96 \%$, respectively) than did sows fed the control diet.

\section{Lactation performance}

As displayed in Table 3, maternal dietary OxBC supplementation during late gestation and lactation did not affect the number of weaned piglets per litter, ADG, pre-weaning survival or the diarrhoea rate of piglets $(P>0.05)$. However, dietary OxBC supplementation tended to enhance litter weight $(P=0.073)$ and individual piglet weight at weaning $(P=0.089)$.

\section{Lactation feed intake and backfat thickness of sows}

There were no differences among treatments for average daily feed intake during lactation, backfat thickness at day 110 of gestation and at day 21 of lactation, and backfat thickness loss during lactation (Table 4). No signs of inappetence or

Table 4. Effects of dietary fully oxidised $\beta$-carotene (OxBC) supplementation during late gestation and lactation on average daily feed intake (ADFI) during lactation and backfat thickness of sows

(Mean values with their standard errors; numbers)

\begin{tabular}{|c|c|c|c|c|c|c|c|c|}
\hline \multirow[b]{3}{*}{ Items } & \multicolumn{7}{|c|}{ OxBC level (mg/kg) } & \multirow[b]{3}{*}{$P$} \\
\hline & \multicolumn{3}{|c|}{0} & \multicolumn{2}{|c|}{4} & \multicolumn{2}{|c|}{8} & \\
\hline & Mean & & SEM & Mean & SEM & Mean & SEM & \\
\hline$n$ & & 50 & & & & & & \\
\hline Sow parity & $4 \cdot 70$ & & 0.40 & $4 \cdot 70$ & 0.39 & $4 \cdot 71$ & 0.38 & 1.000 \\
\hline ADFI during lactation ( $\mathrm{kg} / \mathrm{d}$ per sow) & 3.98 & & 0.12 & 4.11 & 0.08 & $4 \cdot 16$ & 0.07 & 0.234 \\
\hline \multicolumn{9}{|l|}{ Backfat thickness (mm) } \\
\hline Day 110 of gestation & $16 \cdot 19$ & & 0.23 & $16 \cdot 27$ & 0.35 & $16 \cdot 44$ & 0.21 & 0.796 \\
\hline Day 21 of lactation & 13.86 & & 0.18 & 14.07 & 0.29 & 14.29 & 0.19 & 0.389 \\
\hline Loss during lactation & $2 \cdot 33$ & & 0.14 & $2 \cdot 20$ & 0.12 & 2.15 & 0.12 & 0.599 \\
\hline
\end{tabular}




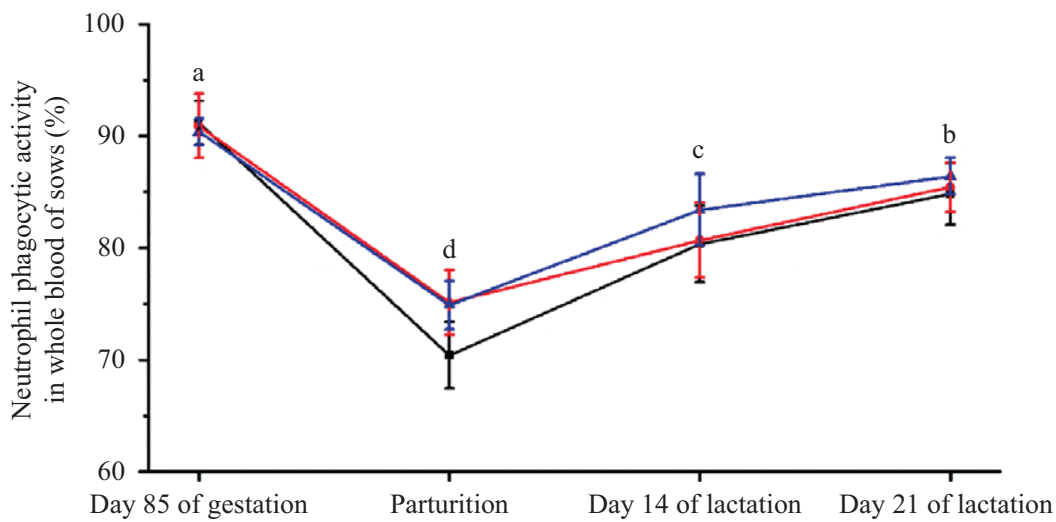

Fig. 1. Effects of dietary fully oxidised $\beta$-carotene (OxBC) supplementation during late gestation and lactation on neutrophil phagocytic activity in whole blood of sows (n 10). ${ }^{a, b, c, d}$ Unlike letters indicate significant difference at each time point regardless of dietary treatments $(n 30) . \longrightarrow, 0 \mathrm{mg} / \mathrm{kg} \mathrm{OxBC;} \longrightarrow$ $8 \mathrm{mg} / \mathrm{kg}$ OxBC.

clinical disease were found in sows throughout the entire feeding period.

\section{Neutrophil phagocytic activity in whole blood of sows}

As described in Fig. 1, the neutrophil phagocytic activity in the whole blood of sows was unaffected by dietary OxBC supplementation $(P>0 \cdot 05)$. Regardless of dietary treatments, the neutrophil phagocytic activity was highest at day 85 of gestation, decreased to its lowest level at parturition and rebounded to a higher value at day 14 and day 21 of lactation $(P<0 \cdot 05)$.

\section{Nutritional composition and somatic cell count in} colostrum and milk

As summarised in Table 5, the nutritional composition and somatic cell count (SCC) in the colostrum and milk of multiparous sows were not influenced by dietary treatments, except for lactose concentration in day 14 milk $(P>0.05)$. There was a trend towards increased lactose concentration in 14-d milk with increasing dietary $\mathrm{OxBC}(P=0 \cdot 071)$.

\section{Immunoglobulin levels in colostrum and milk}

The effects of dietary OxBC supplementation during late gestation and lactation on immunoglobulin concentrations in colostrum and milk of multiparous sows are shown in Table 6. Dietary supplementation with $\mathrm{OxBC}$ greatly enhanced colostrum IgM, IgA and IgG levels $(P<0.05)$ as well as the levels of $\operatorname{IgM}(P<0.05)$ and IgG in 14-d milk $(P=0.052)$. Compared with sows fed $4 \mathrm{mg} / \mathrm{kg}$ OxBC, sows fed $8 \mathrm{mg} / \mathrm{kg}$ OxBC had numerically greater colostrum IgM, IgA and IgG levels and greater IgM and IgG levels in 14-d milk, but those indexes from two groups were not significantly higher $(P>0.05)$.

\section{Cytokine levels in colostrum and milk}

As shown in Table 7, dietary OxBC supplementation during late gestation and lactation decreased TNF- $\alpha$ and IL- 8 levels in the colostrum and TNF- $\alpha$ and IL-18 levels in 14-d milk $(P<0.05)$, while there was a trend towards increased sCD14 in 14-d milk $(P=0.055)$. Compared with sows fed the $4 \mathrm{mg} / \mathrm{kg}$ OxBC diet, sows fed the $8 \mathrm{mg} / \mathrm{kg}$ OxBC diet had numerically decreased TNF- $\alpha$ and IL- 8 in the colostrum and decreased TNF- $\alpha$ in 14-d

Table 5. Effects of dietary fully oxidised $\beta$-carotene (OxBC) supplementation during late gestation and lactation on the nutritional composition and somatic cell count (SCC) in colostrum and milk of sows

(Mean values with their standard errors; numbers)

\begin{tabular}{|c|c|c|c|c|c|c|c|}
\hline \multirow[b]{3}{*}{ Items } & \multicolumn{6}{|c|}{ OxBC level (mg/kg) } & \multirow[b]{3}{*}{$P$} \\
\hline & \multicolumn{2}{|c|}{0} & \multicolumn{2}{|c|}{4} & \multicolumn{2}{|c|}{8} & \\
\hline & Mean & SEM & Mean & SEM & Mean & SEM & \\
\hline$n$ & & & & & & & \\
\hline \multicolumn{8}{|l|}{ Colostrum } \\
\hline Fat (\%) & 3.29 & 0.16 & $3 \cdot 74$ & 0.28 & 3.48 & 0.28 & 0.448 \\
\hline Solid-not-fat (\%) & $20 \cdot 25$ & 0.65 & $19 \cdot 81$ & 0.78 & $20 \cdot 78$ & 0.97 & 0.703 \\
\hline Protein (\%) & $7 \cdot 65$ & 0.24 & $7 \cdot 48$ & 0.31 & $7 \cdot 86$ & 0.37 & 0.690 \\
\hline Lactose (\%) & $11 \cdot 21$ & 0.36 & $10 \cdot 95$ & 0.45 & 11.51 & 0.55 & 0.694 \\
\hline $\operatorname{SCC}\left(\times 10^{6} / \mathrm{ml}\right)$ & $5 \cdot 34$ & 0.37 & 4.93 & 0.34 & 4.98 & 0.39 & 0.696 \\
\hline \multicolumn{8}{|l|}{ 14-d milk } \\
\hline Fat (\%) & 4.96 & 0.40 & $5 \cdot 64$ & 0.31 & $5 \cdot 30$ & $0 \cdot 16$ & 0.300 \\
\hline Solid-not-fat (\%) & 11.40 & 0.32 & $10 \cdot 81$ & 0.25 & $11 \cdot 10$ & 0.23 & 0.195 \\
\hline Protein (\%) & 3.86 & 0.10 & 4.02 & 0.11 & $4 \cdot 13$ & 0.08 & 0.173 \\
\hline Lactose (\%) & $5 \cdot 67$ & 0.13 & 5.93 & 0.12 & 6.09 & 0.11 & 0.071 \\
\hline $\operatorname{SCC}\left(\times 10^{6} / \mathrm{ml}\right)$ & 4.03 & 0.30 & 3.52 & 0.33 & 3.34 & 0.32 & 0.300 \\
\hline
\end{tabular}


Table 6. Effects of dietary fully oxidised $\beta$-carotene (OxBC) supplementation during late gestation and lactation on immunoglobulin levels in colostrum and milk of sows

(Mean values with their standard errors; numbers)

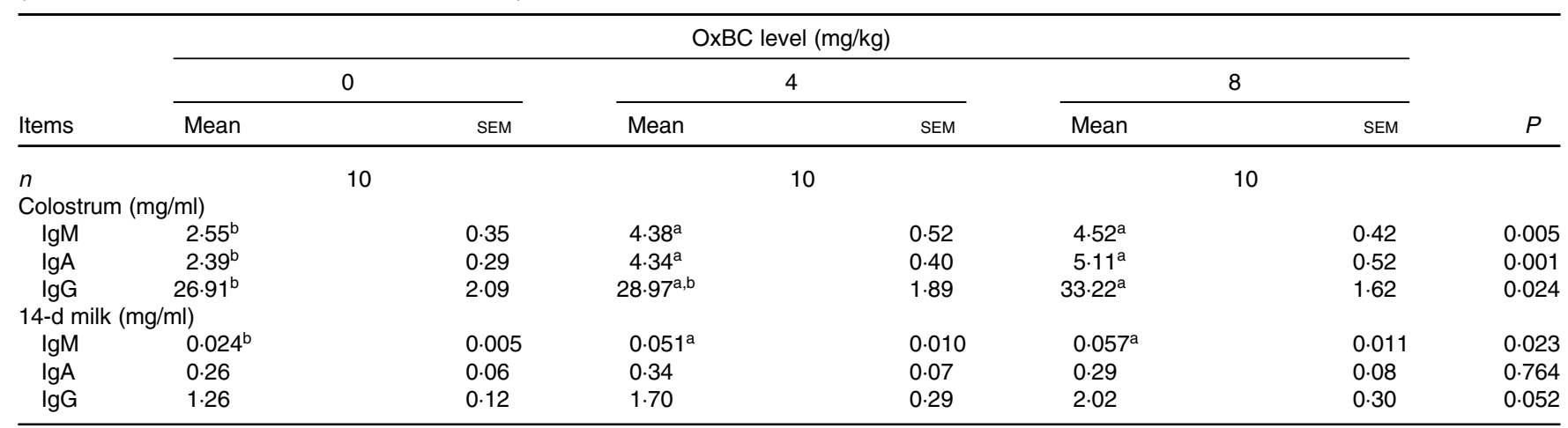

a,b In a row, mean values with unlike superscript letters were significantly different $(P<0.05)$.

Table 7. Effects of dietary fully oxidised $\beta$-carotene (OxBC) supplementation during late gestation and lactation on cytokine levels in colostrum and milk of sows (Mean values with their standard errors; numbers)

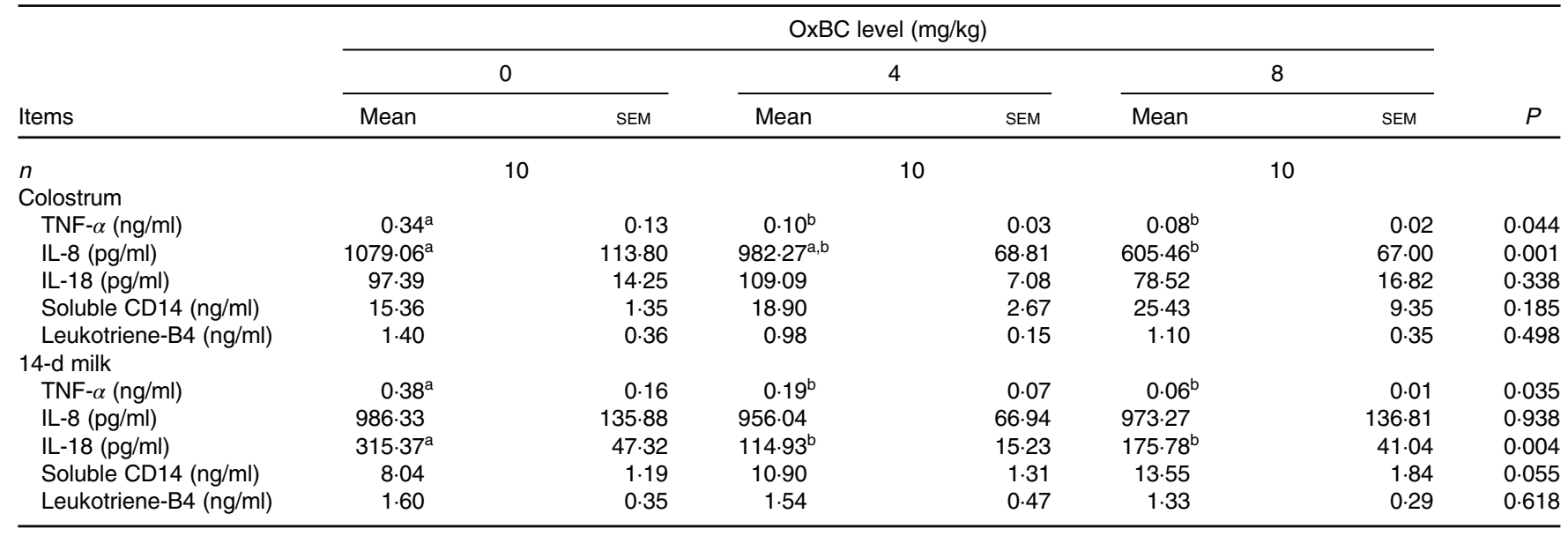

$\mathrm{a}, \mathrm{b}$ In a row, mean values with unlike letters were significantly different $(P<0.05)$.

milk and increased sCD14 in 14-d milk, but those indexes were not significantly different between 4 and $8 \mathrm{mg} / \mathrm{kg}$ OxBC groups $(P>0 \cdot 05)$

\section{Oxidised $\beta$-carotene content in milk}

The OxBC content was measured by quantifying the geronic acid content, which serves as a marker. At day 18 of lactation, we sampled ten sows/treatment with $30 \mathrm{ml}$ milk/sow. However, the minimum milk requirement for the geronic acid measurement is $200 \mathrm{ml}$; therefore, we mixed an identical volume $(20 \mathrm{ml})$ from ten sows to attain sufficient volume $(200 \mathrm{ml})$ for a one-time measurement. The values for geronic acid content were $5.99,7.69$ and $11.02 \mathrm{ng} / \mathrm{ml}$ for the 0,4 and $8 \mathrm{mg} / \mathrm{kg}$ OxBC treatment, respectively, indicating OxBC contents in the milk of $0.30,0.38$ and $0.55 \mu \mathrm{g} / \mathrm{ml}$.

\section{Discussion}

Many studies have reported on the beneficial effects of $\beta$-carotene in sows, which include controlling various maladies causing reproductive failure and enhancing antioxidant capacity $^{(16,17)}$. Kostoglou et al. reported that injecting sows with $\beta$-carotene resulted in an increased number of piglets born alive, while both dietary supplementation (during gestation and lactation) and injection of $\beta$-carotene resulted in increased litter size at weaning ${ }^{(18)}$. Others have shown that dietary $\beta$-carotene supplementation during late pregnancy also improves sow immune status and antioxidant capacity while also increasing the birth weight of piglets ${ }^{(19)}$. The fact that dietary $\beta$-carotene supplementation is known to enhance the accumulation of $\beta$-carotene and vitamin A in plasma and the body tissues leads to the logical conclusion that the reported benefits are the result of direct actions of $\beta$-carotene or its provitamin A activity ${ }^{(20)}$.

Despite the literature reports of its benefits to the productivity and immunity of sows, $\beta$-carotene is not widely used by the commercial swine industry. The lack of widespread application by industry may stem from a lack of consistency regarding $\beta$-carotene benefits. A scientific panel of the European Food Safety Association concluded that there was insufficient scientific evidence to support a proposed benefit of $\beta$-carotene as a feed additive on host immunity, and it cited an inconsistency of effectiveness as the major problem ${ }^{(21)}$. The inconsistency cited in the 
European Food Safety Association report may reflect the fact that the observed benefits, many of which occur independent of $\beta$-carotene's provitamin A activity, are not actually derived directly from $\beta$-carotene itself, but rather from the undetected presence of naturally occurring $\beta$-carotene-oxygen copolymers that have only recently been discovered ${ }^{(6,11,12)}$. The copolymers, which are the major chemical species present in $\mathrm{OxBC}$, are reported to enhance innate immunity and reduce over-zealous inflammatory activity ${ }^{(7,8)}$. Furthermore, previous trials in piglets, dairy calves and broiler chickens have demonstrated the immunological activities of OxBC and their benefits to animal health ${ }^{(8-10)}$. It has been suggested that the copolymers present in $\mathrm{OxBC}$ are the actual active agents responsible for the vitamin A independent benefits of $\beta$-carotene in animals ${ }^{(7)}$.

OxBC is a carotenoid derivative, which is produced by the complete autocatalytic oxidation of $\beta$-carotene ${ }^{(6)}$. The oxidation occurs naturally whenever $\beta$-carotene is exposed to oxygen in air, but for commercial purposes the reaction can be carried out in a controlled manufacturing process. OxBC does not have provitamin A or antioxidant activity, and therefore, its modes of action are distinct from those of $\beta$-carotene. OxBC is herein introduced as a new feed additive that supports immunity and enhances litter and piglet weights at weaning. The geronic acid content is a marker to determine the OxBC content in milk. Geronic acid is an indirect, low molecular weight marker indicating the presence of OxBC. The geronic acid method is described in Burton et $a l^{(12)}$, and the multiplying factor is 50 in going from the geronic acid measurement to the calculated $\mathrm{OxBC}^{(12)}$. The values for geronic acid content were 5.99, 7.69 and $11.02 \mathrm{ng} / \mathrm{ml}$ for the 0,4 and $8 \mathrm{mg} / \mathrm{kg}$ OxBC treatment, respectively, indicating OxBC contents in the milk of $0.30,0.38$ and $0.55 \mu \mathrm{g} / \mathrm{ml}$.

Results of the present study demonstrate that supplementation of sow diets with OxBC has multiple benefits for the sow and nursing piglets. These benefits include increasing immunoglobulin levels and reducing inflammatory markers in colostrum and milk, an apparent increase in milk macronutrient levels, and increased litter and piglet weights at weaning. In addition, the improved growth performance of piglets may also be caused by the increased OxBC intake from milk.

The most notable finding, at the immunological level, was a significant increase in immunoglobulins in colostrum and milk from sows receiving OxBC-supplemented diets. Dietary supplementation with OxBC greatly enhanced colostrum levels of immunoglobulins $\operatorname{IgM}$, IgA and $\operatorname{IgG}(P<0.05)$ as well as the IgM level in milk at day $14(P<0 \cdot 05)$. The antibody (immunoglobulin) complement system offers major antimicrobial protection against a wide range of microbes and confers passive immunity to suckling animals ${ }^{(22)}$. Thus, OxBC supplementation of sow diets resulted in improved transfer of passive immunity to nursing piglets which is beneficial to health and growth of preweaning piglets.

By comparison, dietary supplementation with $\beta$-carotene at 40,60 or $160 \mathrm{mg} / \mathrm{kg}$ of feed was reported to significantly increase the IgG concentration in the colostrum of sows ${ }^{(19)}$. There was also an increase in serum IgG, IgM and IgA concentration for sows in the $160 \mathrm{mg} / \mathrm{kg}$ group at days 95 and 110 of gestation ${ }^{(19)}$. It is interesting to note that the levels of supplementary $\beta$-carotene in the Feng et al. study are five to forty times higher than the levels of OxBC used in the present study ${ }^{(19)}$. Given the propensity of $\beta$-carotene to spontaneously oxidise, it is highly likely that the $\beta$-carotene product used in the Feng et al. study ${ }^{(19)}$, despite being micro-incapsulated, contained low levels of OxBC-like compounds that were unbeknownst to the authors.

An additional benefit of dietary supplementation with OxBC was the reduction in inflammatory cytokines in colostrum and milk combined with an increase in the level of sCD14. Sows in the OxBC-supplemented groups had reduced TNF- $\alpha$ and IL-8 levels in colostrum and lower TNF- $\alpha$ and IL-18 levels in milk $(P<0 \cdot 05)$. There was also a tendency for sCD14, an immune factor that plays an important role in the development of the immune system of the piglet, to be increased in milk from sows receiving supplemental OxBC $(P<0.055)$.

The observed reduction in pro-inflammatory cytokines is consistent with earlier in vitro studies demonstrating that cells treated with OxBC had reduced expression of pro-inflammatory cytokines, including TNF- $\alpha^{(6)}$. Furthermore, in an experiemental model of bovine respiratory disease, dietary supplementation with OxBC increased anti-inflammatory mechanisms in the lungs of Mannhiemia haemolytica-challenged calves. More specifically, there were significant increases in leucocyte apoptosis and the subsequent efferocytosis by macrophages in bronchoalveolar lavage fluid of challenged animals receiving $\mathrm{OxBC}^{(8)}$. These results indicated an anti-inflammatory or pro-resolution activity for OxBC. Importantly, there was no effect of OxBC on the number of circulating leucocytes ${ }^{(8)}$. Perinatal sows are known to suffer from a metabolic syndrome which results in a low-grade systemic inflammatory condition ${ }^{(5)}$. Thus, it is possible that the reduction in pro-inflammatory cytokines observed in sow colostrum and milk occurred as a direct result of OxBC's ability to reduce systemic inflammation in the sow.

In addition to anti-inflammatory activity, OxBC is also reported to possess immune priming functions that relate to increased levels of pathogen pattern recognition receptors such as toll-like receptors two and four (TLR-2, TLR-4) and CD14 as well as potentiation of down-stream innate immune response to pathogen-receptor interaction ${ }^{(7)}$. In a previous dietary supplementation trial with Clostridium perfringens-challenged broiler chickens, birds in the OxBC groups had significantly lower bacterial counts and reduced intestinal lesions relative to controls $^{(10)}$. Therefore, it is also possible that the reduction in inflammatory markers in colostrum and milk observed in the present study occurred as an indirect consequence of OxBC immune priming actions which would ultimately result in a lower level of subclinical infection in the mammary gland via the immune actions of the sow. While it is not possible to definitively conclude whether the reduction in pro-inflammatory cytokines was a direct or indirect effect of OxBC, it can be concluded that supplementation improved the health of the sow mammary gland.

While the improved cytokine status of colostrum and milk likely reflects improved overall health of the sow, there were also positive implications for the nursing piglets, as evidenced by the apparent trend for higher litter and piglet weights at weaning from sows in the OxBC-supplemented groups. To determine why supplementation of sow diets with OxBC improved litter weight and individual piglet weight at weaning, we measured 
the nutritional composition and SCC in colostrum and day 14 milk. The composition and yield of colostrum and milk are key factors determining the growth rate of suckling piglets ${ }^{(23)}$. Dietary supplementation with OxBC tended to increase the lactose concentration in day 14 milk relative to control but had no clear effect on SCC in colostrum or in day 14 milk. As an important component of milk, lactose plays a key role in maintaining the osmotic pressure of milk, and lactose yield is highly correlated with milk yield ${ }^{(24,25)}$. Although milk yield was not measured in the present study, the improvement in litter weight and individual piglet weight at weaning may be at least partially due to higher milk yield from sows in the OxBC groups. There is also a plausible link between the reduction in pro-inflammatory cytokines in colostrum and milk of OxBC-treated sows and the apparent increase in lactose content. High chronic immune system activation in sows is associated with reduced milk nutrients and yield due to the inhibitory actions of pro-inflammatory cytokines on the lactogenic hormones ${ }^{(26)}$. It should be the reduced expression of pro-inflammatory cytokines in the mammary gland to reduce the inhibitory effect. Reduced cytokine levels in milk may be the result of reduced expression of proinflammatory cytokines in the mammary gland.

Additional parameters evaluated in the present study included the phagocytic activity of neutrophils from sows, as well as feed intake, backfat loss and birth weight of piglets. In the present study, regardless of dietary treatments, the neutrophil phagocytic activity was highest at day 85 of gestation, decreased to its lowest level at parturition and rebounded to a higher value at day 14 and day 21 of lactation $(P<0.05)$. This result is consistent with the findings of other studies in sows and indicates that perinatal sows are under a heavy metabolic load and suffer from a metabolic syndrome and reduced immune function ${ }^{(2-4)}$. Dietary supplementation with OxBC did not significantly impact neutrophil activity. Dietary OxBC supplementation also had no significant impact on sow feed intake or backfat loss during lactation. Litter size and piglet birth weights were also unaffected by dietary supplementation with OxBC. These findings are in contrast to a study that showed that dietary supplementation with $\beta$-carotene during late pregnancy improves immune status, the antioxidant capacity of sows and the birth weight of piglets ${ }^{(19)}$. Furthermore, injecting sows with $\beta$-carotene has been shown to increase the number of piglets born alive ${ }^{(18)}$. The most explanation of the difference is that OxBC is devoid of intact $\beta$-carotene and does not possess vitamin A nor the provitamin A or antioxidant activities of $\beta$-carotene, and therefore its mode of actions is unique and distinct relative to those of $\beta$-carotene ${ }^{(6,7)}$. The possibility that similar benefits on sow immunity and reproductive performance could be obtained with longer periods of dietary supplementation with OxBC will be evaluated in future studies carried out over the entire gestation period.

\section{Conclusion}

Dietary supplementation with OxBC during the perinatal period enhanced immunoglobulin levels and reduced inflammatory markers in colostrum and milk. Lactose concentration of milk was also increased, and as a consequence, there was a tendency of increased litter weight and individual piglet weight at weaning for piglets nursed from sows in the OxBC groups. The results also provide a scientific nutritional reference for perinatal mothers due to the biological similarity between pigs and humans.

\section{Acknowledgements}

We thank Dr William Riley for participating in the experimental design and discussion. We are grateful to Dr James G. Nickerson for his help in the presentation of this manuscript.

The present study was supported by the National Key R\&D Program of China (2018YFD0501002). This work was also supported by the National Key R\&D Program of China (no. 2018YFD0500600), National Natural Science Foundation of the P. R. of China (no. 31872364 and no. 31802067) and the Natural Science Foundation of Guangdong Province (no. 2018A030310201).

The contributions of the authors are as follows: J. C. (Jun Chen) and W. G. designed the study. J. C. (Jun Chen), J. C. (Jiaming Chen) and L. C. participated in the animal experiment. Y. Z., Y. L. and H. Q. conducted the research. M. T., S. Z. and F. C. analysed the data. J. C. (Jun Chen) discussed the results and wrote the paper. All authors read and approved the final manuscript.

The authors declare that they have no conflicts of interest.

\section{References}

1. Kim SW, Weaver AC, Shen YB, et al. (2013) Improving efficiency of sow productivity: nutrition and health. J Anim Sci Biotechnol 4, 26.

2. Jakovac-Strajn B, Ihan A, Kopitar A, et al. (2011) Phagocytic activity in blood and proliferation of peripheral blood lymphocytes during the perinatal period in primiparous sows. J Anim Physiol Anim Nutr 95, 328-334.

3. Lin S, Zhang Y, Long Y, et al. (2016) Mammary inflammatory gene expression was associated with reproductive stage and regulated by docosahexenoic acid: in vitro and in vivo studies. Lipids Health Dis 15, 215.

4. Cheng C, Wei H, Xu C, et al. (2018) Metabolic syndrome during perinatal period in sows and the link with gut microbiota and metabolites. Front Microbiol 9, 1989.

5. Das UN (2010) Metabolic syndrome is a low-grade systemic inflammatory condition. Expert Rev Endocrinol Metab 5, 577-592.

6. Burton GW, Daroszewski J, Nickerson JG, et al. (2014) $\beta$-Carotene autoxidation: oxygen copolymerization, non-vitamin A products, and immunological activity. Can J Chem 92, 305-316.

7. Johnston JB, Nickerson JG \& Daroszewski J (2014) Biologically active polymers from spontaneous carotenoid oxidation: a new frontier in carotenoid activity. PLOS ONE 9, e111346.

8. Duquette SC, Fischer CD, Feener TD, et al. (2014) Antiinflammatory effects of retinoids and carotenoid derivatives on caspase-3-dependent apoptosis and efferocytosis of bovine neutrophils. Am J Vet Res 75, 1064-1075.

9. Hurnik D, Daroszewski J \& Burton G (2011) Determination of the effect of a fully oxidized $\beta$-carotene dietary supplement on the immune system and growth performance of weaned pigs. American Association of Swine Veterinarians 42nd Annual Meeting, Phoenix, Arizona. pp. 277-279. 
10. Kang M, Oh J, Cha S, et al. (2018) Efficacy of polymers from spontaneous carotenoid oxidation in reducing necrotic enteritis in broilers. Poult Sci 97, 3058-3062.

11. Schaub P, Wüst F \& Koschmier J, et al. (2017) Nonenzymatic $\beta$-carotene degradation in provitamin A-biofortified crop plants. J Agric Food Chem 65, 6588-6598.

12. Burton GW, Daroszewski J, Mogg TJ, et al. (2016) Discovery and characterization of carotenoid-oxygen copolymers in fruits and vegetables with potential health benefits. J Agric Food Chem 64, 3767-3777.

13. Miller RE \& Ullrey DE (1987) The pig as a model for human nutrition. Annu Rev Nutr 7, 361-382.

14. Roura E, Koopmans SJ, Lallès JP, et al. (2016) Critical review evaluating the pig as a model for human nutritional physiology. Nutr Res Rev 29, 60-90.

15. National Research Council (2012) Nutrient Requirements of Swine, 11th rev. ed. Washington, DC: National Academy of Press.

16. Kumar S, Pandey A, Rao MM, et al. (2010) Role of $\beta$ carotene/ vitamin A in animal reproduction. Vet World 3, 236.

17. Szczubiał M (2015) Effect of supplementation with vitamins E, C and $\beta$-carotene on antioxidative/oxidative status parameters in sows during the postpartum period. Pol J Vet Sci 18, 299-305.

18. Kostoglou P, Kyriakis S, Papasteriadis A, et al. (2000) Effect of $\beta$-carotene on health status and performance of sows and their litters. J Anim Physiol Anim Nutr 83, 150-157.

19. Feng J, Deng F, Yu Y, et al. (2009) Effects of $\beta$-carotene microcapsules on reproducibility, immunity and antioxidant capability in late-pregnancy sows. J Zhejiang Univ 35 , 665-669.

20. Schweigert FJ, Buchholz I, Schuhmacher A, et al. (2001) Effect of dietary $\beta$-carotene on the accumulation of $\beta$-carotene and vitamin A in plasma and tissues of gilts. Reprod Nutr Dev $\mathbf{4 1}$, $47-55$.

21. EFSA Panel on Additives and Products or Substances used in Animal Feed (FEEDAP) (2012) Scientific Opinion on the safety and efficacy of beta-carotene as a feed additive for all animal species and categories. EFSA J 10, 2737.

22. Korhonen H \& Marnila Pgill HS (2000) Milk immunoglobulins and complement factors. Br J Nutr 84, 75-80.

23. Chen J, Zhang F, Guan W, et al. (2019) Increasing selenium supply for heat-stressed or actively cooled sows improves piglet preweaning survival, colostrum and milk composition, as well as maternal selenium, antioxidant status and immunoglobulin transfer. J Trace Elem Med Biol 52, 89-99.

24. Cant J, Trout D, Qiao F, et al. (2002) Milk synthetic response of the bovine mammary gland to an increase in the local concentration of arterial glucose. J Dairy Sci 85, 494-503.

25. Miglior F, Sewalem A, Jamrozik J, et al. (2007) Genetic analysis of milk urea nitrogen and lactose and their relationships with other production traits in Canadian Holstein cattle. J Dairy Sci $90,2468-2479$.

26. Sauber T, Stahly T \& Nonnecke B (1999) Effect of level of chronic immune system activation on the lactational performance of sows. J Anim Sci 77, 1985-1993. 